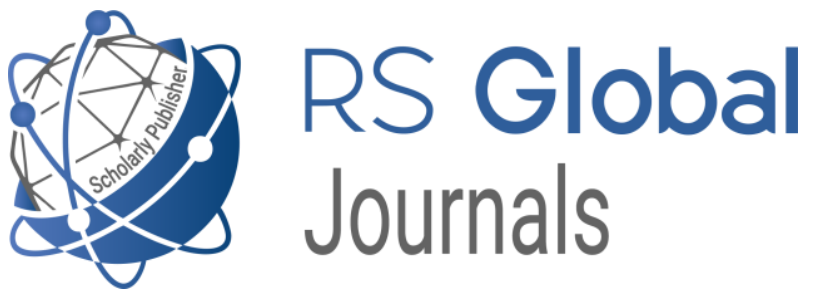

Scholarly Publisher

RS Global Sp. z O.O.

ISNI: 0000000484952390

Dolna 17, Warsaw, Poland 00-773

Tel: +48226022703

Email: editorial_office@rsglobal.pl

JOURNAL International Journal of Innovative Technologies in Social Science

p-ISSN

$2544-9338$

e-ISSN

2544-9435

PUBLISHER

RS Global Sp. z O.O., Poland

ARTICLE TITLE

HEALTH SYSTEMS MANAGEMENT AND FINANCIAL SUSTAINABILITY IN GEORGIA

$\operatorname{AUTHOR}(\mathbf{S})$

Manana Maridashvili, Davit Meparishvili, Ekaterine Sanikidze

Manana Maridashvili, Davit Meparishvili, Ekaterine Sanikidze. (2021) Health Systems Management and Financial Sustainability

ARTICLE INFO in Georgia. International Journal of Innovative Technologies in Social Science. 3(31). doi:

10.31435/rsglobal_ijitss/30092021/7644

DOI

https://doi.org/10.31435/rsglobal_ijitss/30092021/7644

RECEIVED

22 June 2021

ACCEPTED

13 August 2021

PUBLISHED

18 August 2021

LICENSE

This work is licensed under a Creative Commons Attribution

4.0 International License.

(C) The author(s) 2021. This publication is an open access article. 


\title{
HEALTH SYSTEMS MANAGEMENT AND FINANCIAL SUSTAINABILITY IN GEORGIA
}

\author{
Manana Maridashvili, PhD in Business administration, Professor, Georgian National University, \\ Tbilisi, Georgia, ORCID ID: https://orcid.org/0000-0002-2798-9643 \\ Davit Meparishvili, PhD in Business administration, Invited Professor, Ilia State University, Tbilisi, \\ Georgia, ORCID ID: https://orcid.org/0000-0001-7454-2521 \\ Ekaterine Sanikidze, Doctoral student of Business administration, Georgian Technical University. \\ Tbilisi, Georgia, ORCID ID: https://orcid.org/0000-0003-0466-1845
}

\section{DOI: https://doi.org/10.31435/rsglobal_ijitss/30092021/7644}

\section{ARTICLE INFO}

Received 22 June 2021

Accepted 13 August 2021

Published 18 August 2021

\section{KEYWORDS}

health care system, primary health care, universal health care, financial sustainability, reforms, world health organization.

\begin{abstract}
The article discusses and evaluates Health systems management and financial sustainability in Georgian Health Institutions, also provides the analyses of the state of health care in the conditions of Georgia. Improving and further developing the primary health care system is crucial to controlling the financial sustainability and growth costs of the health care system, including increasing funding and access to funding, and strengthening the role of the planned outpatient sector - family physician, As well as effective management of patients with chronic diseases. Activating the role of the physician, thus enabling the early detection of various diseases, as well as the effective management of patients with chronic diseases. At the same time, we consider a significant increase in funding for medicines, which will reduce the aggravation of a number of diseases at the level of inpatient treatment, thus saving considerable financial resources in the universal program, which is spent in the inpatient sector, and also improves public health.
\end{abstract}

Citation: Manana Maridashvili, Davit Meparishvili, Ekaterine Sanikidze. (2021) Health Systems Management and Financial Sustainability in Georgia. International Journal of Innovative Technologies in Social Science. 3(31). doi: 10.31435/rsglobal_ijitss/30092021/7644

Copyright: (C) 2021 Manana Maridashvili, Davit Meparishvili, Ekaterine Sanikidze. This is an openaccess article distributed under the terms of the Creative Commons Attribution License (CC BY). The use, distribution or reproduction in other forums is permitted, provided the original author(s) or licensor are credited and that the original publication in this journal is cited, in accordance with accepted academic practice. No use, distribution or reproduction is permitted which does not comply with these terms.

Introduction. Health care as an important sector of the state, which includes a system of political, economic, social, legal, scientific, medical, sanitary and hygienic, anti-epidemic and cultural measures, organizes, provides and aims to protect the physical and mental health of each person, healthy Maintain and strengthen life with medical care, disease prevention, treatment, and life extension.

Healthcare systems are organizations designed to meet the health needs of the target population. According to the World Health Organization (WHO), a functioning health care system requires an effective funding mechanism, a well-educated and adequately paid workforce, and reliable information on which to base rational decisions and policies, well-equipped medical facilities with quality medicines and technologies [1].

At the same time, healthcare is an integral part of international development. An effective health care system can make a significant contribution to the development of a country's economy and industrialization. Ensuring a healthy life and promoting well-being for all and at all ages, creating an effective health care system, its perfection and development in Georgia are still associated with certain problems [2].

Health care reforms. Since the beginning of health care reforms, especially since 1995, significant changes have taken place and significant progress has been made in Georgia in improving the health of the population, taking into account key risk factors and reducing health risks. During this 
period, uniform rules for receiving and distributing income, common rules and methods of remuneration for workers were developed and introduced in medical institutions, significant changes took place in the governing structure, a new legal health system was established, a health insurance system was established, and health policy makers were separated. Organizational and financial management of medical institutions, decentralization of healthcare system management, autonomy of healthcare institutions, etc.

Since 2006, the government has carried out market-oriented reforms. Priority was given to state funding by providing access to medical care for vulnerable (targeted) segments of the population. Direct funding of medical institutions through state programs has replaced the model of financing with insurance and medical vouchers.

The development of the hospital sector began in 2007 and almost completely upgraded the medical infrastructure, privatizing most of the medical service providers, using the public-private partnership model and in the form of direct privatization. It is noteworthy that the private investment in medical infrastructure during this period amounted to more than $\$ 500$ million. Healthcare funding has been increased from GEL 80 million to GEL 380 million. The share of illegal payments has been significantly reduced from $67 \%$ to $6 \%$ and the level of corruption in the healthcare sector in general. Out-of-pocket payments were reduced from $90 \%$ to $75 \%$.

It is noteworthy that since 2013, the state course on health care has changed dramatically: the provision of health services to target groups has been replaced by universal coverage of services and a foundation for universal access to health care has been created for every citizen. With existing state insurance and had no private insurance. Unlike the universal health care program, other state insurance programs were implemented by private insurance companies, the beneficiaries of which were only the socially vulnerable, retirees, children under 5 , students, children with disabilities and severely disabled persons. In 2014, all other state health insurance programs were abolished and their beneficiary citizens also joined the universal health care program. Consequently, private insurance companies no longer participated in state projects from this period [3].

It is true that according to statistics, the number of clinics increased from 2011 to 2019, however, the surplus medical infrastructure was often created without taking into account the medical needs of the population and it should be noted that the rapid increase in the number of clinics from the beginning Was the result of a health program [4].

The share of private, profit-oriented hospitals in Georgia in the total number of hospitals is $86 \%$ and is quite high compared to many developing and developed countries, the remaining $14 \%$ (mainly specialized medical institutions such as psychiatric, drug, etc.) are state-owned. Owned. We consider it important to promote the development of other forms of ownership, in particular non-profit (non-profit) and public-private partnership medical organizations, which play an important role in developed countries and thus increase competition between forms of ownership of medical organizations. Bringing the system closer to the existing experience of the countries of the world [5].

The number of hospital beds exceeds the needs of the population. In 2019, only $49 \%$ of the beds were loaded, which is significantly lower than the EU (77\%) and CIS (83\%) averages. All this indicates the inefficient use of invested capital and other resources. Small and possibly low-efficiency facilities were mainly introduced to the market, which did not have a significant impact on the market share of the leading facilities, although it did reduce the effective utilization rate of the installed capacity.

Funding for health programs. It should be noted that funding for health programs is growing every year and in 2019 will exceed one billion GEL. Its largest share, more than 70\%, is universal health program spending. It is true that after the launch of the universal healthcare program in Georgia, the share of out-of-pocket payments in total healthcare expenditures decreased, but in 2019, about $56 \%$ of healthcare expenditures were still paid out of pocket, which is still high compared to EU $(16 \%)$ and regional (38\%). It should be noted that according to the Health Policy Development Policy Document, the Government of Georgia will reduce the share of out-of-pocket payments to $30 \%$ by 2030 and achieve a share of more than 5\% of public spending on GDP, according to the DRG (Diagnosis-Related Groups). Similar diseases (e.g., diseases of the cardiovascular system) united in one nosological group) plan to increase the share of inpatient cases reimbursed by $100 \%$ and the share of primary health care and prevention expenditures by $40 \%$ in total costs [6].

It is noteworthy that despite the significant increase in health expenditures in recent years, according to available data, among European and regional countries, Georgia is still one of the last 
places in the share of public health expenditures in both total health expenditures (2017 - 38\%) and GDP (2017 - 2.9\%) and in the state budget (2017 - 10\%) [7].

Despite a number of health care reforms in terms of financial stability and risk assessment, it is important to note that the sector has excess production capacity and is not being used effectively. According to the statistics of 2019, the bed load rate in Georgia is $49 \%$, which is significantly lower than the average rates of the European Union (77\%) and the CIS (83\%). One of the reasons for the low efficiencies is the fragmentation of the sector. $60 \%$ of facilities account for only $10.9 \%$ of hospitalizations, while the average size of hospitals is 3 times lower than the OECD rate in terms of bedding. Clearly, all this has a negative impact on the financial performance of the sector. It is important to improve the cost-effectiveness of health services and to introduce the DRG (diagnostic grouping) model of financing hospitals and emergency care services, to introduce new standards of hospital infrastructure and human resources, which will significantly reduce the efficiency of the sector.

Despite significant improvements in accessibility, the demand for primary health care in Georgia is still low, with an outpatient number of 3.6 per capita in 2019, well behind the EU (7.0).

At the same time, there is an abundance of doctors and a shortage of nurses in Georgia. There are only 0.6 nurses per doctor in Georgia and 2 to 5 nurses in European countries. As a result, Georgian doctors are 3-5 times less productive than their counterparts in European countries, which means that they serve fewer patients [8].

The state seeks to manage health care expenditures through uniform tariffs (Resolutions 520 and others), which must be methodologically sound, quality-oriented and periodically adjusted, otherwise their disregard would jeopardize the sector's financial stability, quality of service and patients' financial security.

An important challenge is the spread of COVID-19 in Georgia and its effective management; It should be noted that medical consumables are a major component of sector expenditures and account for approximately $25 \%$ of revenues. Clearly, in such conditions, the need for additional equipment (gloves, goggles and other protective equipment) to protect against a pandemic increases the cost of medical care. Medical supplies are mostly imported and the depreciation of the gel further increases their cost. At the same time, increased utility tariffs - from 2021 electricity tariffs for companies by $65-75 \%$, and water tariffs will increase by about $48 \%$ compared to $2018-20$.

Under such conditions, the deterioration of the financial condition of the sector and, consequently, the investment attractiveness is expected to endanger the liquidity and sound financial condition of the sector in the conditions of the above growing costs, if the tariff is not adjusted periodically.

As it is known, the best health condition is very important for raising the welfare of the population and the socio-economic development of the country. The main goals of the World Health Organization (WHO) member states, including Georgia, are to improve the health of the population, protect them from financial risks and redistribute their burden, use existing resources efficiently and respond to health needs in a timely manner.

Conclusions. Improving and further developing the primary health care system is crucial to controlling the financial sustainability and growth costs of the health care system, including increasing funding and access to funding, and strengthening the role of the planned outpatient sector - family physician, As well as effective management of patients with chronic diseases. At the same time, we consider it important to increase funding for medicines, which in turn will reduce the aggravation of a number of diseases at the level of inpatient treatment, thus saving a considerable amount of money spent in the universal program and improving the health of the population.

The effective functioning of the Georgian healthcare sector envisages the improvement of such important issues as: improvement of the legal framework, improvement of the quality of medical services, improvement of the existing mechanisms for ensuring quality and safety in terms of infrastructure and human resources (improvement of state permits, licenses and certification system). , Accreditation and increase of remuneration, rational use of state investments, introduction and dissemination of innovative and high-tech products / services, projects, accurate determination of the volume of medical services that will be fully funded by the state and balanced with real opportunities, better transparency of state programs and Ensuring effective communication with the public using all means of modern mass media [7,8] and the optimal solution of other topical directions, have a positive impact BS to achieve the improvement of the health system of the country, the health of the population and to raise the standard of living. 


\section{REFERENCES}

1. Baltussen, R., Jansen, M. P., Mikkelsen, E., Tromp, N., Hontelez, J., Bijlmakers, L., \& Van der Wilt, G. J. (2016). Priority setting for universal health coverage: We need evidence-informed deliberative processes, not just more evidence on cost-effectiveness. International Journal of Health Policy and Management, 5(11), 615-618.

2. Barasa, E. W., Molyneux, S., English, M., \& Cleary, S. (2015). Setting healthcare priorities at the macro and meso levels: A framework for evaluation. International Journal of Health Policy and Management, 4(11), 719-732.

3. Chee, G., Pielemeier, N., Lion, A., \& Connor, C. (2013). Why differentiating between health system support and health system strengthening is needed. The International Journal of Health Planning and Management, 28(1), 85-94.

4. Daniels, N., \& Sabin, J. (1997). Limits to health care: Fair procedures, democratic deliberation, and the legitimacy problem for insurers. Philosophy \& Public Affairs, 26(4), 303-350.

5. Glassman, A., Chalkidou, K., Giedion, U., Teerawattananon, Y., Tunis, S., Bump, J. B., \& PichonRiviere, A. (2012). Priority-Setting Institutions in Health. Global Heart, 7(1), 13-34.

6. Jamison, D. T., Alwan, A., Mock, C. N., Nugent, R., Watkins, D. (2018). Universal health coverage and intersectoral action for health: Key messages from Disease Control Priorities, 3rd edition. Lancet (London, England), 391(10125), 1108-1120

7. Kapiriri, L., Lee, N.-M., Wallace, L. J., \& Kwesiga, B. (2019). Beyond cost-effectiveness, morbidity and mortality: A comprehensive evaluation of priority setting for HIV programming in Uganda. BMC Public Health, 19(1), 359.

8. Li, R., Hernandez-Villafuerte, K., Towse, A., Vlad, I., \& Chalkidou, K. (2016). Mapping priority setting in health in 17 countries across Asia, Latin America, and sub-Saharan Africa. Health Systems \& Reform, 2(1), 71-83. 